\title{
NK cells and multiple myeloma-associated endothelial cells: molecular interactions and influence of IL-27
}

\author{
Alessandra Dondero ${ }^{1}$, Beatrice Casu ${ }^{1}$, Francesca Bellora $^{1}$, Angelo Vacca ${ }^{2}$, Annunziata \\ De Luisi' ${ }^{2}$, Maria Antonia Frassanito ${ }^{2}$, Claudia Cantoni ${ }^{1,3,4}$, Silvia Gaggero ${ }^{1}$, Daniel \\ Olive $^{5}$, Alessandro Moretta ${ }^{1}$, Cristina Bottino ${ }^{1,3, *}$, Roberta Castriconi ${ }^{1,4, *}$ \\ ${ }^{1}$ Department of Experimental Medicine (DIMES), University of Genova, 16132 Genova, Italy \\ ${ }^{2}$ Department of Biomedical Sciences and Human Oncology, University of Bari, 70124 Bari, Italy \\ ${ }^{3}$ Istituto Giannina Gaslini, 16147 Genova, Italy \\ ${ }^{4}$ Center of Excellence for Biomedical Research (CEBR), University of Genova, 16132 Genova, Italy \\ ${ }^{5}$ U1068, CRCM, Immunity and Cancer, INSERM, 13009 Marseille, France \\ *Co-seniorship
}

Correspondence to: Cristina Bottino, email: Cristina.Bottino@unige.it

Keywords: multiple myeloma, endothelial cells, NK cells, IL-27, PD-LS

Received: June 30, $2016 \quad$ Accepted: March 27, $2017 \quad$ Published: April 12, 2017

Copyright: Dondero et al. This is an open-access article distributed under the terms of the Creative Commons Attribution License (CC-BY), which permits unrestricted use, distribution, and reproduction in any medium, provided the original author and source are credited.

\section{ABSTRACT}

Angiogenesis represents a hallmark of tumor progression in Multiple Myeloma (MM), a still incurable malignancy. Here we analyzed the activity of cytokinestimulated NK cells against tumor-associated endothelial cells isolated from bone marrow aspirates of MM patients with active disease (MMECs). We show that NK cells activated with optimal doses of IL-15 killed MMECs thanks to the concerted action of multiple activating receptors. In particular, according to the high expression of PVR and Nectin-2 on MMECs, DNAM-1 actively participated in target recognition. Interestingly, in MMECs the surface density of PVR was significantly higher than that detected in endothelium from patients with $M M$ in complete remission or with monoclonal gammopathy of undetermined significance (MGUS). Importantly, IL27, which unlike IL-15 does not display pro-angiogenic properties, maintained or increased the NK cell functions induced by suboptimal concentrations of IL-15. NK cell properties included killing of MMECs, IFN-Y production as well as a peculiar increase of NKp46 expression on NK cell surface. Finally, IL-27 showed a striking capability of up-regulating the expression of PD-L2 and HLA-I on tumor endothelium, whereas it did not modify that of PD-L1 and HLA-II.

Our results suggest that cytokine-activated endogenous or adoptively transferred NK cells might support conventional therapies improving the outcome of MM patients.

\section{INTRODUCTION}

In the last decades important advancements in the treatment of different malignances have led to significant improvement in patients' survival. A variety of therapies are currently available including those targeting specific pathways involved in the growth and survival of cancer cells or tumor-associated stromal cells such as endothelial cells. A pro-tumoral crosstalk between cancer and endothelial cells occurs and is essential for tumor growth. In multiple myeloma (MM), an incurable malignancy of monoclonal plasma cells [1], angiogenesis represents a hallmark of tumor progression and antiVEGF drugs, alone or in combination with other agents, are currently used. In some patients however, available therapeutic approaches resulted in limited benefits and in a short-lasting tumor regression. Thus, many efforts have been made to evaluate additional therapeutic protocols aimed at obtaining a more durable tumor control in different malignances including MM. New strategies consist of immunotherapeutic approaches including the strengthening of the function of endogenous Natural 
Killer (NK) cells or the adoptive transfer of "armed" or activated NK cells [2-5]. These cells are cytotoxic members of the Innate Lymphoid Cell (ILCs) family [6, 7] and have been shown to play a crucial role in tumor surveillance also due to their capability of killing tumor cells including those with stem cell like properties [8-11]. The mechanisms allowing the NK-mediated recognition of tumor cells have been largely clarified and consist of the cooperation of different triggering receptors that are engaged by specific ligands upregulated or de novo expressed on transformed cells [3, 11, 12]. Activating NK receptors are represented by NKp46 (CD335), NKp30 (CD337) and NKp44 (CD336) (collectively termed natural cytotoxicity receptors, NCR), DNAM-1 (CD226) and NKG2D (CD314) [3, 13]. Although viral glycoproteins have been identified as ligands for NCR, their cellular ligands are not fully defined [14]. Two molecules, the mixed-lineage leukemia (MLL5) [15] and B7-H6 [16] have been found to be expressed on a wide panel of tumors [17] and represent cellular surface ligands of NKp44 and NKp30, respectively. It is of note however, that different evidences suggest that NKp30 would be able to recognize additional, still undefined, tumor-associated ligand(s). NKG2D recognizes MICA/B and ULBPs [12] stress inducible molecules de-novo expressed after tumor transformation and virus infection. DNAM-1 binds PVR (CD155) and Nectin-2 [18], two members of the Nectin family that are also recognized by Tactile [19] and TIGIT [20]. PVR and Nectin-2 are over-expressed in tumors of different histotype and their interaction with DNAM-1 is non-redundant and crucial to obtain an efficient tumor cell killing [21-24]. Accordingly, different studies highlighted the importance of DNAM-1/ligands interactions in the establishment of the activating immunological synapse that allows tumor recognition by both NK and T cells [25-28].

The possible effect of NK-cell based therapeutic approaches in killing of tumor-associated endothelial cells with the consequent reduction of the vascular network remains to be determined.

In the present study we analyzed the NK cell activity against tumor-associated endothelial cells (EC) isolated from bone marrow aspirates of MM patients in active phase (MMECs). We evaluated the susceptibility of MMECs to killing mediated by IL-15-stimulated NK cells and dissected the molecular interactions occurring between effector and target cells. Moreover, we investigated the immunostimulatory effects of IL-27 [29] that, unlike IL-15, does not display pro-angiogenic properties [30, 31]. Finally, considering that NK cell activation might result in vivo in a cytokine storm responsible for the activation of immune checkpoints, $[32,33]$ we analyzed in MMECs the constitutive and cytokine-induced surface expression of Programmed Death Ligands (PD-Ls) and HLA class I and II [34-36].

\section{RESULTS}

\section{DNAM-1 actively participates to the killing of MMECs mediated by rIL-15-activated NK cells}

Tumor-associated endothelial cells were isolated from bone marrow (BM) aspirates of nine Multiple Myeloma Patients in active phase (Table 1) [37]. MMECs were analyzed for the susceptibility to lysis mediated by peripheral blood mononuclear cells (PBMCs) of healthy donors activated with optimal doses of rIL-15 (20 ng/ml) (Figure 1A). Overall, activated PBMCs killed the MMECs analyzed and HLA class I molecules had a poor protective role as demonstrated by the lack of significant differences observed in the presence of the anti-HLA-I mAb (Figure 1A). It is of note however that a certain degree of heterogeneity in the susceptibility of MMECs to activated PMBCs could be appreciated. Indeed, MMEC3 and MMEC4 showed a susceptibility to lysis comparable to that of EA, a prototypic tumor endothelial cell line used as control, whereas MMEC1 and MMEC2 were more resistant (Figure 1A).

Assuming a predominant role of NK lymphocytes in the killing of MMECs by rIL-15 activated PBMCs, we analyzed the susceptibility of MMECs to lysis mediated by highly purified activated NK cells (Figure 1B). Moreover, in order to analyze the possible contribution of the different activating NK receptors in the recognition of MMECs, cytolytic assays were performed in the presence of $\mathrm{mAbs}$ able to specifically disrupt the interactions between the receptors (on NK cells) and their ligands (on target cells). Similar to EA, MMECs were highly susceptible to killing mediated by rIL-15 activated NK cells, a process that depended on the cooperation of various activating receptors (Figure 1B). In particular, NKG2D and DNAM-1 contributed to the killing of MMEC3 and a significant inhibition of lysis was observed only after the combined mAb-mediated masking of both molecules. NKG2D was not involved in MMEC5 recognition, whereas DNAM-1 played a major role in the NK-mediated cytotoxicity, as its $\mathrm{mAb}$-mediated masking resulted in a significant reduction of lysis. Moreover, mAb-mediated masking of NKp30 and NKp46 significantly reduced the lysis demonstrating the involvement of these receptors in killing of MMEC5 (Figure 1B). The NK-mediated recognition of EA cells involved the four different activating receptors thus recapitulating what observed in endothelial cells derived from MM patients. A similar scenario was observed using endothelial cells obtained from patients with monoclonal gammopathy of undetermined significance (MGECs). In these experiments we used the CD107a assay that was more suitable to preserve the viability of target cells. As shown in Supplementary Figure 1, rIL-15 stimulated NK cells degranulated in the presence of MGECs (and in the presence of EA, used as control) and DNAM-1, NKG2D, NKp30 and NKp46 receptors clearly cooperated in the process. 
Table 1: Endothelial cells analyzed in the study

\begin{tabular}{|c|c|c|c|c|}
\hline Endothelial cells & Disease & Phase & Age & Gender \\
\hline MMEC1 & MM & Active & 55 & Male \\
\hline MMEC2 & MM & Active & 63 & Female \\
\hline MMEC3 & MM & Active & 70 & Male \\
\hline MMEC4 & $\mathrm{MM}$ & Active & 67 & Female \\
\hline MMEC5 & $\mathrm{MM}$ & Active & 73 & Female \\
\hline MMEC6 & MM & Active & 55 & Male \\
\hline MMEC7 & MM & Active & 65 & Male \\
\hline MMEC8 & MM & Active & 60 & Female \\
\hline MMEC9 & $\mathrm{MM}$ & Active & 63 & Female \\
\hline cr-MMEC & $\mathrm{MM}$ & Complete remission & 71 & Male \\
\hline MGEC1 & MGUS & & 47 & Male \\
\hline MGEC2 & MGUS & & 59 & Male \\
\hline MGEC3 & MGUS & & 61 & Female \\
\hline MGEC4 & MGUS & & 75 & Female \\
\hline MGEC5 & MGUS & & 53 & Male \\
\hline MGEC6 & MGUS & & 75 & Male \\
\hline MGEC7 & MGUS & & 64 & Male \\
\hline IDAEC & IDA & & 56 & Female \\
\hline
\end{tabular}

The endothelial cells analyzed in this study were derived from bone marrow aspirates of patients with Multiple Myeloma in active phase (MMEC1-9) or complete remission (cr-MMEC), patients with monoclonal gammopathy of undetermined significance (MGEC1-7) and a patient with anemia due to iron deficiency (IDAEC).

\section{MMECs and EA cell line express the ligands of DNAM-1 activating receptor}

MMECs were analyzed for the surface expression of the ligands of activating receptors known to regulate NK cell functions including cytolytic activity. The gating strategy is shown in Supplementary Figure 2. For comparison, the analysis was performed on endothelial cells derived from $\mathrm{BM}$ of patients with $\mathrm{MM}$ in complete remission (cr-MMEC), monoclonal gammopathy of undetermined significance (MGEC 1-5) or anemia due to iron deficiency (IDAEC).

In all cells analyzed NKG2D-ligands were either undetectable or expressed at very low levels (Table 2). In particular, according to the involvement of NKG2D in NK-mediated lysis (see Figure 1B) MMEC3 expressed MICA, ULBP-2 and ULBP-3. The latter two ligands were also detected in the EA cell line whereas MMEC5, which was killed in an NKG2D-independent manner, did not express any of the NKG2D ligands analyzed. All endothelial cells analyzed expressed good levels of PVR and Nectin-2 (Table 2), ligands of DNAM-1 receptor involved in the killing of MMECs and EA (see Figure 1B). Interestingly, in MMECs and EA the surface density of PVR was significantly higher than in cr-MMEC, MGECs and IDAEC (Figure 2A). Accordingly, MMECs and EA but not the other endothelial cells analyzed were stained by the DNAM1-Fc soluble receptor (Figure 2B).
In spite of the clear involvement of NKp30 in the NK-mediated lysis of some MMECs and EA cells, none of the endothelial cells analyzed was stained by the NKp30Fc soluble receptor (Figure 2B), which efficiently bound the B7-H6 specific ligand on B7-H6+ cell transfectants and K562 cell line (Supplementary Figure 3A). EA cell line was characterized by a very low level of B7-H6 transcript, comparable to that detected in immature Dendritic cells (iDC), whose interaction with NK cells is mostly NKp30dependent [38, 39] (Supplementary Figure 3B). Lack of staining of NKp30-Fc soluble receptor on MMECs might be due to the poor surface expression of B7-H6, not sufficient to bind NKp30-Fc soluble receptor, but capable of engaging the native NKp30 receptor. Alternatively, both MMECs and iDC may express an additional, not yet identified, NKp30 ligand that is not recognized by the NKp30-Fc soluble receptor.

\section{rIL-27 plus suboptimal doses of rIL-15 enhance NK cell cytotoxicity against tumor endothelial cells}

NK cells stimulated with optimal doses of rIL-15 displayed cytotoxicity against all MM-associated endothelial cells analyzed, an effect that was accompanied by the upregulated expression of CD69 activation marker (Figure 3B and 3C), NKG2D (Figure 3D) and NKp30 (Figure $3 \mathrm{E}$ ) and by a modest but significant production of IFN- $\gamma$ (Figure 3H). However, IL-15 might exert 
unwanted in vivo side effects due to its strong proangiogenic activity. Thus, we analyzed the function of NK cells cultured in the presence of rIL-27 $(100 \mathrm{ng} / \mathrm{ml})$, which has been described to combine immunostimulatory and anti-angiogenic properties. As shown in Figure 3, the stimulatory capability of rIL-27 was lower than that of rIL-15. In particular, rIL-27 induced a slight increase in NK cell-mediated killing of EA cells (Figure 3A), a modest increase in the surface expression of CD69 and NKG2D, and did not stimulate the release of IFN- $\gamma$. It is of note, however, that rIL-27 caused a peculiar upregulation of the NKp46 receptor (Figure 3F). When used in combination with rIL-15, rIL-27 did not improve CD69 and NKG2D upregulation but significantly increased the cytolytic activity, the surface expression of NKp30 and the IFN- $\gamma$ production as compared to rIL-15 alone (Figure 3 ). DNAM-1 expression was not modified by rIL-27 or rIL-15 used either alone or in combination (Figure 3G).

To determine the dose of cytokines suitable to induce NK cell activation minimizing pro-angiogenic side effects, NK cells were treated with rIL-27 in combination with decreasing concentration of rIL-15, ranging from 20 to
$1 \mathrm{ng} / \mathrm{ml}$ (Figure 4). NK cells stimulated with rIL-27 and the lowest rIL-15 concentration used $(1 \mathrm{ng} / \mathrm{ml})$ showed a significant increased expression of CD69 (in terms of both $\%$ of positive cells and MFI) and levels of degranulation in the presence of EA cells that reached those observed in the presence of optimal doses of rIL-15. Moreover, rIL-27 promoted an upregulation of DNAM-1 expression (Figure 4C) that progressively increased by reducing the concentration of rIL-15. The ability of rIL-27 to increase NK cell degranulation in the presence of suboptimal doses of rIL-15 (1 ng/ml) was confirmed using as targets both MMECs and MGECs (Figure 5).

\section{rIL-27 up-regulates PD-L2 and HLA class I expression in tumor endothelial cells}

We analyzed whether the positive effects of the rIL$15^{1 \mathrm{ng}}$-rIL-2 $7^{100 \mathrm{ng}}$ combination on NK cell functions could be associated with side effects such as the up-regulation of ligands capable to inhibit the NK cell-mediated attack.

The EA cell line was analyzed for the expression of the PD-Ls and HLA-II immune-checkpoints molecules,
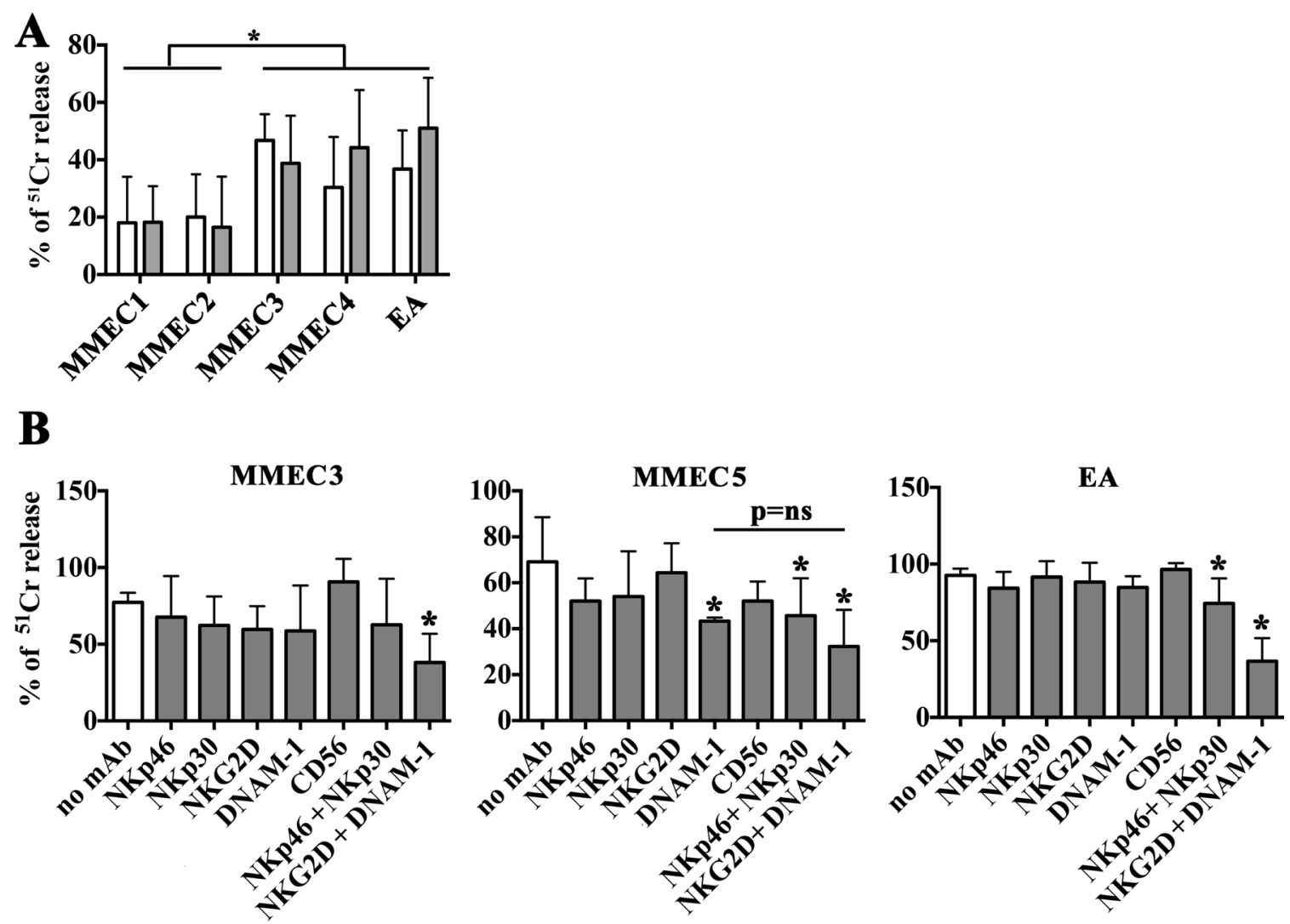

Figure 1: Susceptibility of MMECs to NK-mediated killing and activating receptors involved. (A) PBMCs from 3 healthy donors were stimulated with rIL-15 $(20 \mathrm{ng} / \mathrm{ml})$ and analyzed for their cytolytic activity $\left({ }^{51} \mathrm{Cr}\right.$ release assay) against MMECs derived from 4 different patients (MMEC1-4), (E:T ratio 80:1) in the absence (white bars) or in the presence of anti-HLA-I mAbs (gray bars). Mean (3 healthy donors in duplicate), 95\% confidence intervals and significance are indicated. ${ }^{*} p<0.05$. (B) IL-15 activated NK cell populations were analyzed for their cytolytic activity $\left({ }^{51} \mathrm{Cr}\right.$ release assay) against MMECs and EA cell line (E:T ratio 20:1) in the absence (white bars) or in the presence of $\mathrm{mAbs}(10 \mu \mathrm{g} / \mathrm{ml})$ specific for the indicated activating NK receptors used alone or in combination. Mean (3 healthy donors in duplicate), $95 \%$ confidence intervals and significance are indicated. ${ }^{*} p<0.05$. 
Table 2: NKG2D and DNAM-1 ligands expression in endothelial cells

\begin{tabular}{|l|c|c|c|c|c|c|c|}
\hline \multicolumn{2}{c}{ ULBP-1 } & ULBP-2 & ULBP-3 & ULBP-4 & MICA & PVR & Nectin-2 \\
\hline MMEC1 & $(-)$ & 10 & 11 & $(-)$ & $(-)$ & 186 & 40 \\
\hline MMEC2 & $(-)$ & ND & ND & ND & ND & 147 & 43 \\
\hline MMEC3 & $(-)$ & 7 & 13 & $(-)$ & 12 & 93 & 44 \\
\hline MMEC4 & $(-)$ & $(-)$ & 10 & $(-)$ & ND & 93 & 24 \\
\hline MMEC5 & $(-)$ & $(-)$ & $(-)$ & $(-)$ & $(-)$ & 65 & 23 \\
\hline Cr-MMEC & $(-)$ & $(-)$ & $(-)$ & $(-)$ & $(-)$ & 38 & 36 \\
\hline MGEC1 & $(-)$ & 12 & $(-)$ & $(-)$ & $(-)$ & 57 & 24 \\
\hline MGEC2 & ND & $(-)$ & 9 & ND & ND & 35 & 21 \\
\hline MGEC3 & $(-)$ & 10 & 10 & 13 & $(-)$ & 49 & 19 \\
\hline MGEC4 & $(-)$ & $(-)$ & $(-)$ & 6 & $(-)$ & 61 & 40 \\
\hline MGEC5 & $(-)$ & 6 & $(-)$ & ND & ND & 57 & 13 \\
\hline IDAEC & ND & $(-)$ & $(-)$ & ND & ND & 10 & 14 \\
\hline EA & $(-)$ & 12 & 24 & $(-)$ & $(-)$ & 257 & 57 \\
\hline
\end{tabular}

Endothelial cells used in this study were analyzed by flow cytometry for the expression of the indicated ligands. Values indicate the MFI. Undetectable $=(-), \mathrm{ND}=$ not determined. For EA cell line values represent the mean of 10 different experiments.

as well as of HLA-I. As shown in Figure 6, EA cells constitutively expressed PD-L1, PD-L2 and HLA-I. Similar to what has been demonstrated in tumor cells $[34,40]$, rIFN- $\gamma$ up-regulated the PD-Ls and HLA-I expression and de novo induced that of HLA-II, whereas rTNF $\alpha$ was effective only in the induction of HLA-I expression.

EA cells were treated with culture supernatants derived from NK cells stimulated with the rIL-15 ${ }^{1}$ ng rIL-2 $7^{100}$ ng combination. EA cells did not modify the expression of PD-L1 and HLA-II, whereas they showed upregulation of PD-L2 and HLA-I (Figure 6) at levels comparable to those obtained using rIFN- $\gamma$. It is of note that a similar effect was obtained using supernatants from NK cells stimulated with rIL-2 $7^{100 \mathrm{ng}}$ but not with rIL-15 $5^{1 \mathrm{ng}}$ (Figure 6). Moreover, negligible amounts of IFN- $\gamma$ were detected in the supernatants of NK cells stimulated with rIL-1 $5^{1 \mathrm{ng}}$ and rIL-2 $7^{100 \mathrm{ng}}$, both used alone or in combination (Supplementary Table 1). Overall the data suggested that the increased expression of PD-L2 and HLA-I in EA cells treated with NK supernatants was mainly rIL-27 dependent and IFN- $\gamma / \mathrm{IL}-15$ independent. To confirm this hypothesis, EA cells were directly stimulated with the cytokines either alone or in combination (Figure 7 and Supplementary Figure 4). rIL-27 alone did not modify the expression of PD-L1 and HLA-II, whereas increased that of PD-L2 and HLA-I that reached levels comparable to those obtained using the rIL-15 ${ }^{\text {1ng-rIL-2 }} 7^{100}$ ng combination. On the contrary, rIL-15 alone had no effect even at the highest $(20 \mathrm{ng} / \mathrm{ml})$ concentration used.

The rIL-27 capability of up-regulating HLA-I and PDL2 molecules in tumor endothelium was confirmed using three different MMECs that were treated with rIL-27100 ng (or IFN- $\gamma$, as control) (Figure 8). According to results obtained on EA, rIL-27 did not significantly modify the
PD-L1 expression whereas it up-regulated HLA-I expression in all MMECs, although at different extent. Increased PD-L2 expression was detected in MMEC7 that derived from a patient with $\mathrm{MM}$ in progression and unresponsive to chemotherapy. In line with results on EA, IFN- $\gamma$ induced PD-L1 and HLA-I expression on MMEC6 and MMEC7. Interestingly however, on MMEC8 derived from a patient in relapse IFN- $\gamma$ increased PD-L1 but not HLA-I expression.

\section{DISCUSSION}

Multiple Myeloma remains an incurable disease and novel therapeutic strategies did not lead to a survival higher than 5 years in the adult [41]. Some benefits have been achieved using drugs such as lenalidomide that can exert several immunomodulatory effects, including the exacerbation of NK cell-mediated cytotoxicity against MM [42]. In vitro studies and clinical trials have also explored the possible efficacy of novel strategies combining standard treatments with emerging therapies aimed to interrupt receptors/ligands interactions such as PD1/PD-L1 [43] or KIRs/HLA-I [44], which are capable of limiting the anti-tumor function of immune effectors. NKp46, NKG2D and DNAM-1 activating receptors recognize specific ligands on MM cell surface and unchain the anti-MM activity of NK cells $[45,46]$. In particular, as for other malignancies [21, 22], a pivotal role in the NK-mediated aggression of MM is played by DNAM-1/PVR interactions. These are required for optimal anti-MM efficacy of standard therapies based on the administration of cyclophosphamide and bortezomib. Moreover, it has been shown that different classes of therapeutic agents upregulate DNAM-1 as well as 
NKG2D ligands [47, 48], thus strengthening the concept that NK cells might truly represent powerful adjuvant arms against MM.

Our present study suggests that NK cell-based immunotherapy might also be effective in MM patients because of the capability of NK cells to kill tumorassociated endothelial cells, which are involved in neoangiogenesis and represent a source of soluble factors involved in paracrine loops mediating plasma cell proliferation and spread [49, 50]. We showed that activated NK cells efficiently killed MMECs (and MGECs) thanks to the cooperation of multiple triggering receptors. These include NKp30 whose known ligand B7-H6, however, is virtually absent on tumor endothelium, suggesting the possible existence of novel unidentified NKp30 specific ligand/s. NKG2D ligands were weakly expressed on MMECs surface, whereas all MMECs analyzed expressed good levels of both PVR and Nectin-2, ligands of DNAM that clearly contributed to killing of MMECs. A striking exception was represented by MMEC1 and MMEC2 that resulted poorly susceptible to lysis despite the expression of high levels of PVR. DNAM-1/PVR interaction is crucial for recognition and killing of different tumors [3]. It is of note however that its action could be counteracted by the engagement of TIGIT $[20,51]$ an inhibitory receptor which recognizes nectin-3 as well as PVR and nectin-2, with higher affinity than DNAM-1 [51]. Thus the different susceptibility to killing of $\mathrm{PVR}^{\text {high }}$ MMECs might be
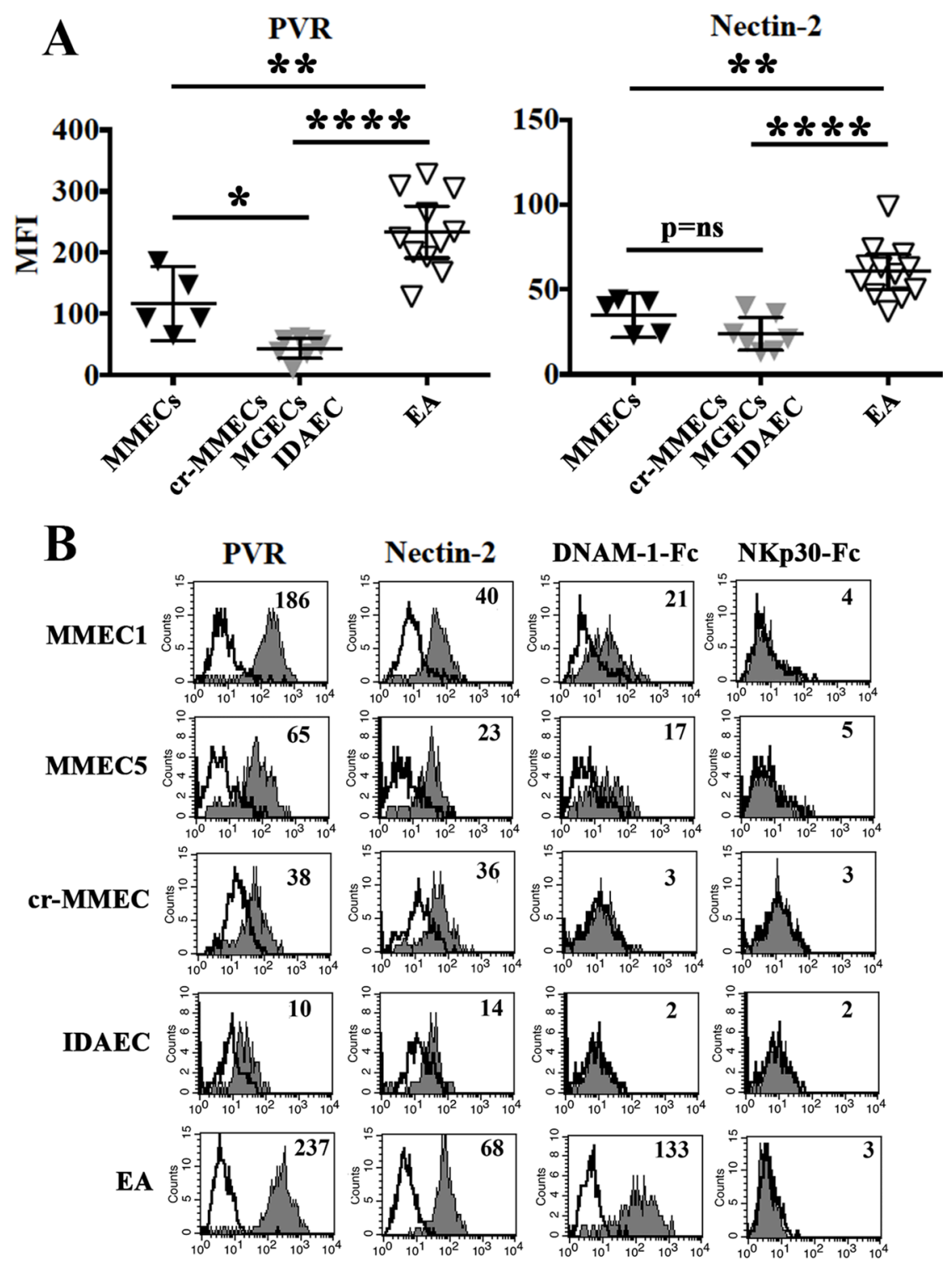

Figure 2: PVR and nectin-2 expression in MMECs and normal endothelial cells. (A) MMECs (black triangles), cr-MMEC, MGECs, IDAEC (gray triangles) and EA (white triangles) were analyzed by flow cytometry for the expression of PVR and Nectin-2. Mean and $95 \%$ confidence intervals are indicated. ${ }^{*} p<0.05,{ }^{*} p<0.0001, * * * * p<0.001, p=$ ns means not significant. (B) Representative cytofluorimetric analysis of PVR, Nectin-2, DNAM-1-Fc and NKp30-Fc staining in MMECs, cr-MMEC, IDAEC and EA. White profiles refer to cells incubated with isotype-matched mAbs. Value inside each histogram indicates the Median Fluorescence Intensity (MFI). 
linked to different combinations of PVR-specific paired receptors on NK cells [51]. Another possibility is that in some patients the function of TIGIT may dominate due to the expression of nectin-3 on MMECs. Both hypotheses are currently under investigation.

In line with data obtained from the immunohistochemical analysis of primary glioblastoma specimens [8], PVR showed a high expression in tumorassociated endothelium from MM BM aspirates. In a physiological context, DNAM-1/PVR interactions have been shown to promote the transendothelial migration process of monocytes [52]. It would be of interest to understand whether the high expression of PVR in MMECs might improve migration of monocytes, which in the tumor microenvironment tend to differentiate into macrophages and acquire a M2 tumor-promoting functional polarization $[53,54]$. Moreover, PVR expression might directly favor the function of MMECs thus contributing to the formation
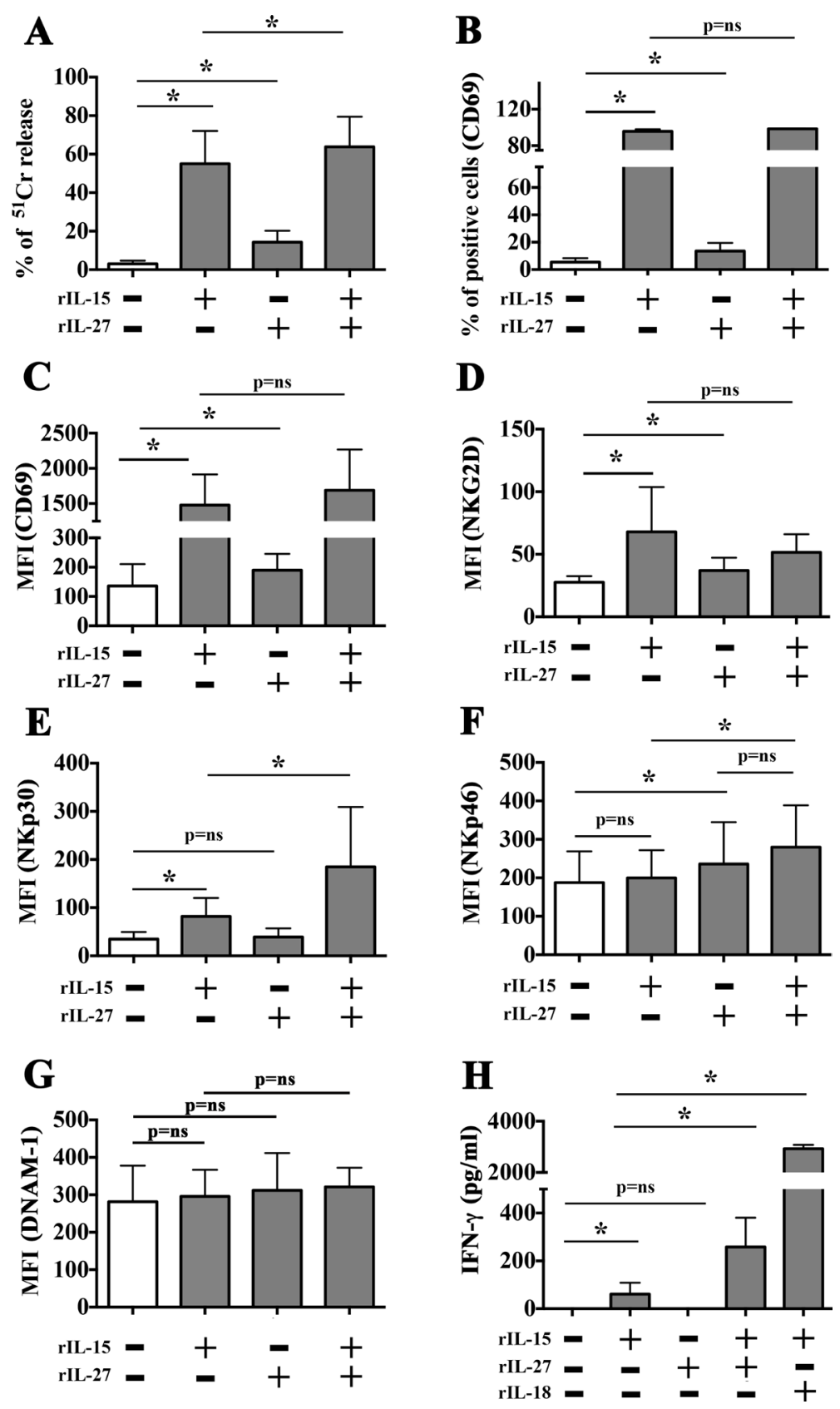

Figure 3: Comparison between rIL-27 and rIL-15-mediated stimulation of resting NK cells. NK cells purified from healthy donors were stimulated with rIL-15 (20 ng/ml) and rIL-27 (100 ng/ml) used alone or in combination. Cells were analyzed for (A) cytotoxicity against EA cells $\left({ }^{51} \mathrm{Cr}\right.$ release assay, E:T ratio 20:1), (B-G) expression of the indicated surface molecules (flow cytometry). Culture supernatants were analyzed for the presence of IFN- $\gamma$ (ELISA assay) (H). Mean and 95\% confidence intervals are indicated. ${ }^{*} p<0.05, p=$ ns means not significant. Data shown are pooled from 6 independent experiments performed using NK cells from 6 unrelated healthy donors. 

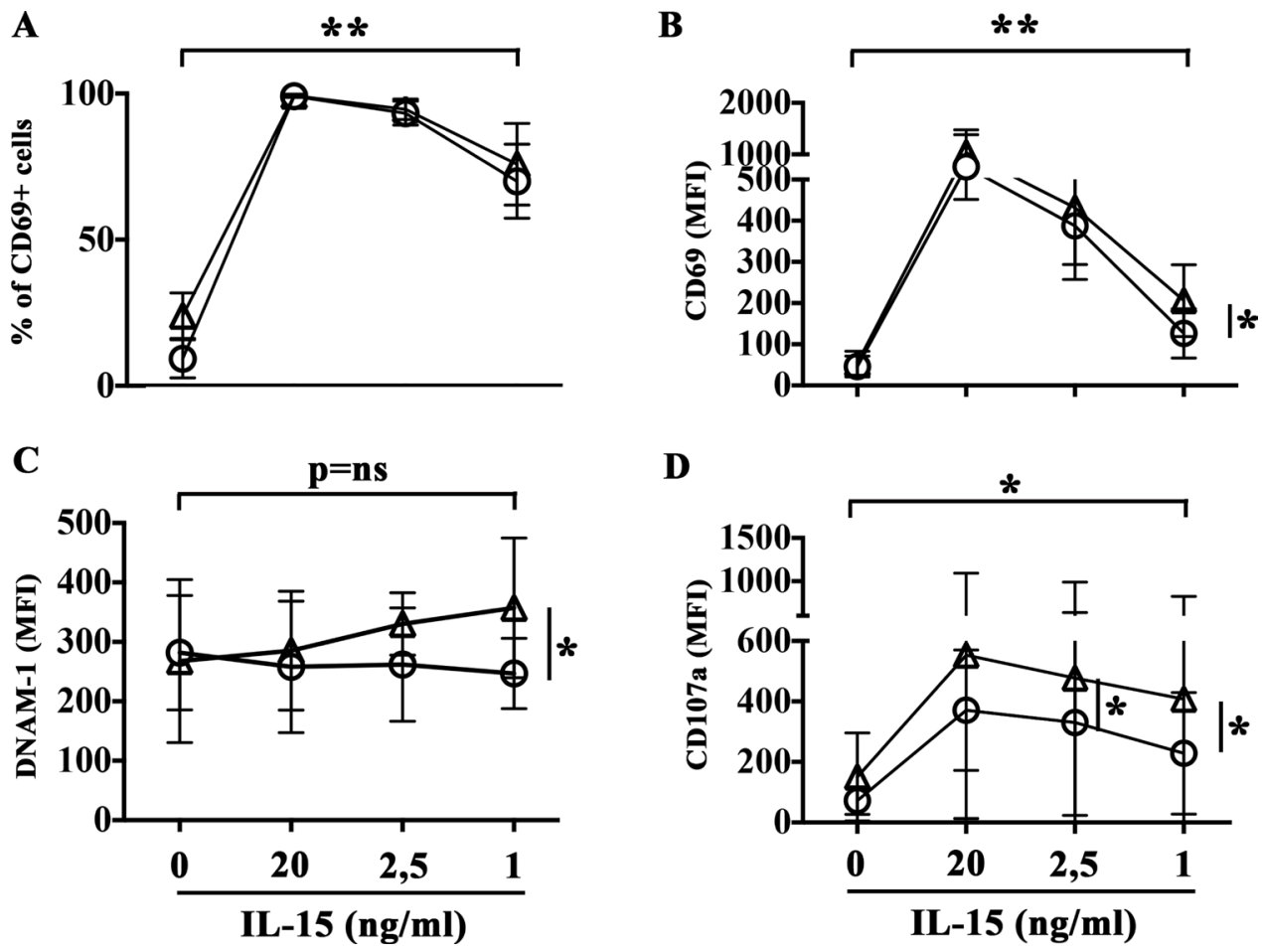

Figure 4: rIL-27 plus suboptimal doses of rIL-15 induce NK cell activation. NK cells purified from healthy donors were stimulated with decreasing concentrations of rIL-15 alone (circle) or in combination with rIL-27 (100 ng/ml) (triangle). Cells were analyzed for (A-C) surface phenotype (flow cytometry), (D) release of cytotoxic granules in the presence of EA cells (CD107a assay). Mean and $95 \%$ confidence intervals are indicated. ${ }^{*} p<0.05,{ }^{*} p<0.01 . p=$ ns means not significant. Data shown are pooled from 6 independent experiments performed using NK cells from 6 unrelated healthy donors.
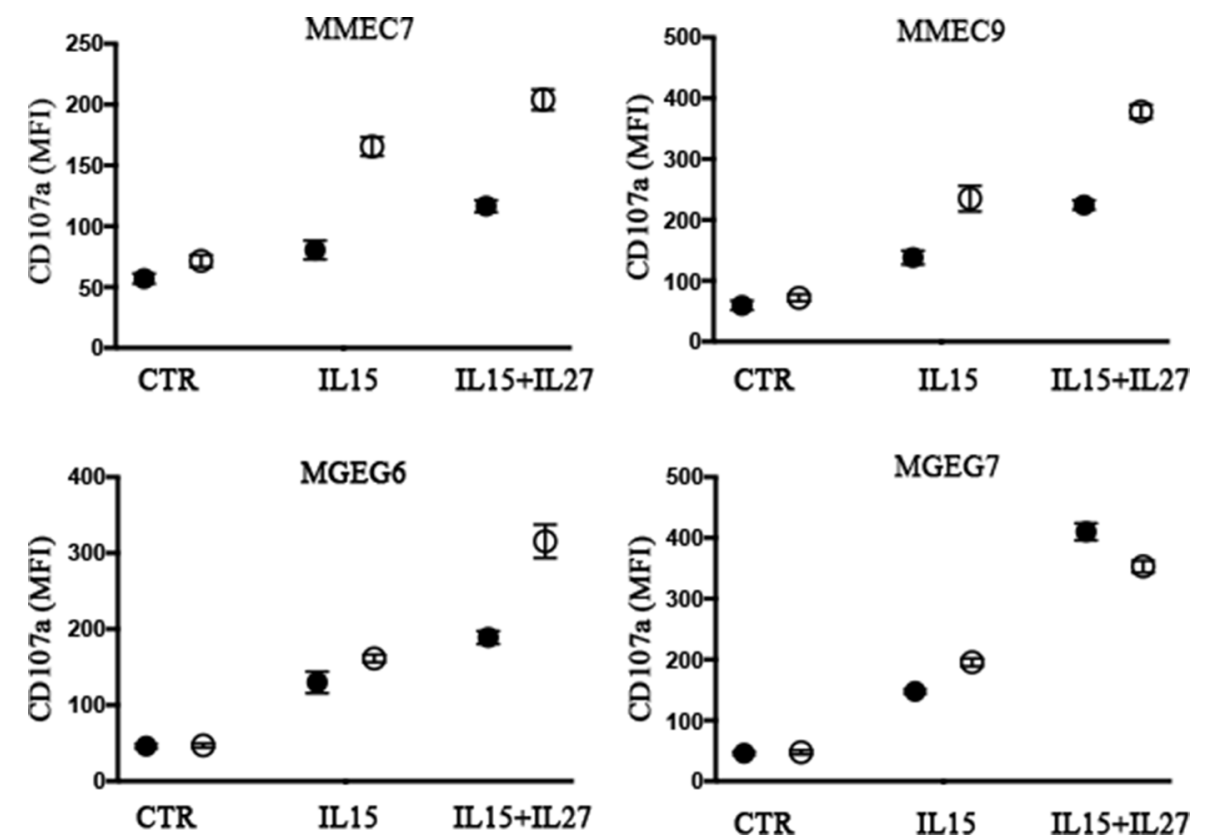

Figure 5: NK cell degranulation in the presence of MMECs and MGECs is increased by rIL-27 and suboptimal concentrations of rIL-15. NK cell populations derived from 2 healthy donors (black and white circles) were stimulated with suboptimal concentrations $(1 \mathrm{ng} / \mathrm{ml})$ of rIL-15 alone or in combination with rIL-27 (100 ng/ml). Cells were analyzed for degranulation (CD107a assay) in the presence of the indicated MMECs and MGECs. Controls (CTR) represent NK cell degranulation of NK cells stimulated with rIL-15 and rIL-27 in the absence of target. Data shown are pooled from 2 independent experiments. Mean are indicated. 
of the complex architecture of tumor vasculature. In this context, different studies showed that PVR improve tumor cell invasion, being localized at the migrating cellular front together with actin and alphav-integrin, known mediators of motility and adhesion [55-57]. Thus, it should be taken into consideration that therapies upregulating PVR expression could on one side potentiate the NK cellmediated killing by improving the formation of effective immune synapses, on the other they may favor functional capabilities of MM and MMECs.

DNAM-1/PVR interactions also occur during the crosstalk between NK cells and Dendritic cells (DC) $[58,59]$ or Macrophages $[60,61]$. During their activation these antigen presenting cells (APC) release different cytokines capable of amplifying NK (and T) cell-mediated responses. These include IL-27 that is of interest in tumor immunology because it combines immunostimulatory and anti-angiogenic properties [30, 31]. We have analyzed the effects of IL-27 on NK cell functions, using the cytokine alone or in combination with IL-15. IL-15 represents a promising immunostimulatory adjuvant for therapies $[62,63]$, and a clinical grade formulation is currently available. However, different data suggested that IL-15 is also endowed with strong pro-angiogenic effects $[64,65]$.
According to previous data, we showed that optimal doses of IL-15 efficiently stimulate NK cells and increase their killing of MMECs. Interestingly, a similar cytolytic potential was observed in NK cells stimulated with IL-27 and suboptimal doses of IL-15 (IL-15 ${ }^{1 \mathrm{ng}}$ and IL-2 $7^{100 \mathrm{ng}}$ ). This effect was paralleled by a trend toward the increased expression of DNAM-1, NKp30, NKG2D and NKp46 activating receptors. In this context, and according with previous published data [66], the upregulation of NKp46 in NK cells was mainly IL-27-dependent.

In some instances, IL-27 did not ameliorate the effect of optimal doses of IL-15. For example, a significant increase of DNAM-1 expression could be appreciated only when IL-27 was used in combination with suboptimal doses of IL-15 (see Figures 3 and 4). This observation could be partially due to the fact that, in NK cells, IL-15and IL-27-mediated signals share some transducing molecules such as JAK1 and STAT5 [67, 68]. Moreover, IL-15 might play a role in regulating IL-27R expression and/or function (under investigation).

NK cells stimulated with IL-27 and suboptimal doses of IL-15, release negligible amounts of IFN- $\gamma$, which is considered the best inducer of HLA-I molecules as well as of the PD-Ls immune-checkpoints ligands [34].

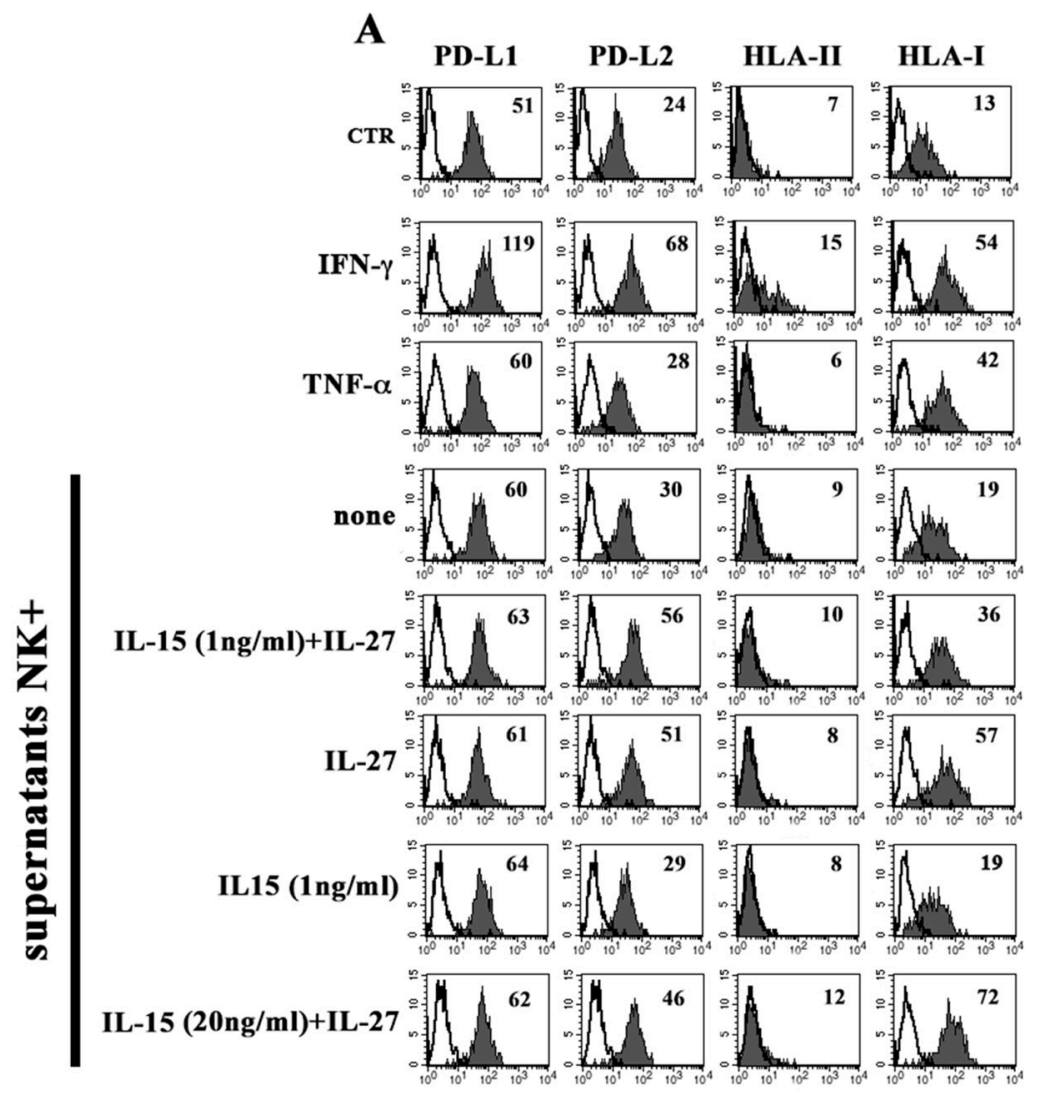

B
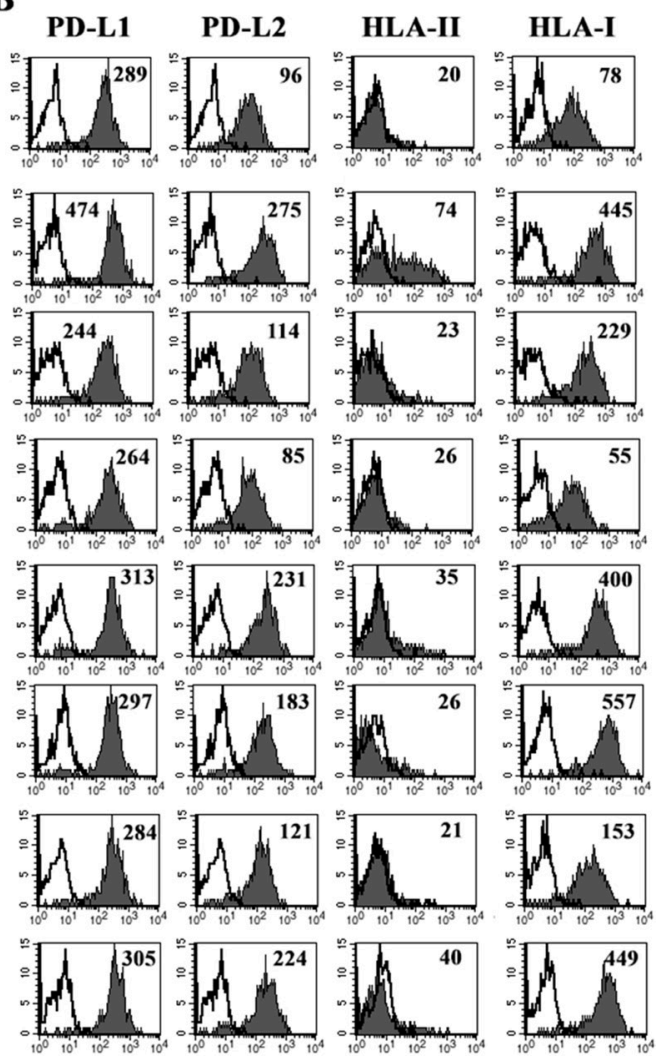

Figure 6: Constitutive or inducible expression of PD-Ls, HLA-II and HLA-I in EA cell line. The EA cell line untreated (CTR), treated with IFN- $\gamma, \mathrm{TNF}-\alpha$ or culture supernatants from NK cells unstimulated (none) or stimulated with the indicated cytokines, was analyzed by flow cytometry for the expression of PD-Ls, HLA-II and HLA-I. Panel A and B show two independent experiments performed using NK cells purified from two unrelated healthy donors. White profiles refer to cells incubated with isotype-matched mAbs. Values inside each histogram indicate the MFI. 
In EA and MMECs, IL-27 (either alone or in combination with IL-15 ${ }^{\text {1ng }}$ ) did not upregulate the expression of PD-L1 or induce that of HLA-II. On the other hand, it upregulated the expression of HLA-I, as previously demonstrated in normal endothelium (HUVEC cells) [69]. Moreover our study highlighted a peculiar function of this cytokine, i.e. the capability of upregulating the expression of PD-L2 on tumor endothelium. It is of note that previous published data suggest that IL-27 function might vary depending on target cell type and cytokine milieu. Indeed, IL-27 has been shown to drive upregulation of HLA-I also in chronic eczema keratinocytes that produced IL-27, but it promoted PD-L1 expression in different cell types including CD4+ and CD8+ T cells, monocytes, DC and tumor cells [29, 30, $70]$. Thus, similar to IFN- $\gamma$ (and TNF- $\alpha$ ), IL-27 might exert possible side effects modulating the expression in MMECs of HLA-I, which downregulates the NK cell function, and PD-L2 that controls the duration and amplitude of both $\mathrm{CD} 8+\mathrm{T}$ and NK cell functions. In this context, it has been shown that in MM patients more than $50 \%$ of peripheral blood NK cells express PD-1 [43], the PD-Ls receptor, although at levels lower than $\mathrm{PD}^{+} \mathrm{NK}$ cells detected in normal individuals or in different pathological conditions [72]. Thus, standard or emerging therapeutic approaches should not disregard the possible induction of a cytokine storm that might shape immune responses against tumor cells and/or tumor-associated endothelium. As for IFN- $\gamma$ [71] the IL-27 capability of upregulating immune checkpoint ligands on tumor endothelium, may greatly vary among patients. Notably, during anti-tumor immune responses IL-27 may act earlier than IFN- $\gamma$, being a cytokine produced by innate cells such as macrophages and DC.

\section{MATERIALS AND METHODS}

\section{Patients}

Bone marrow (BM) aspirates were obtained from nine MM patients fulfilling the International Myeloma Working Group diagnostic criteria for multiple myeloma (MM). MM patients, enrolled at diagnosis (MM1-6, MM9), in progression because unresponsive to therapy (MM7), in relapse (MM8), were characterized by active, symptomatic disease (D\&S stage II-III). Additional BM aspirates were obtained from a MM patient in complete/ objective remission (cr-MM), seven patients with monoclonal gammopathy of undetermined significance (MGUS), and a patient with anemia due to iron deficiency (IDA). Approval from the Ethics Board was obtained ( $\left.\mathrm{N}^{\circ} 4220 / 2013\right)$, and patients were asked to provide their written informed consent in accordance with the Declaration of Helsinki.

\section{Cells used in the study}

Primary endothelial cells (ECs) were obtained from BM of patients as described [37]. Briefly, ECs were purified from BM-derived mononuclear cells by immunoselection, using magnetic microbeads (Dynal, Oslo, Norway) coated with Ulex europaeus agglutinin-1 lectin (UEA-1, Sigma Chemical), whose receptor is selectively and highly expressed by endothelial cells. ECs bound to microbeads were cultured in complete DMEM medium supplemented with $20 \%$ of heatinactivated fetal bovine serum (FBS) to allow cells to adhere, spread and grow. Endothelial cells were growth

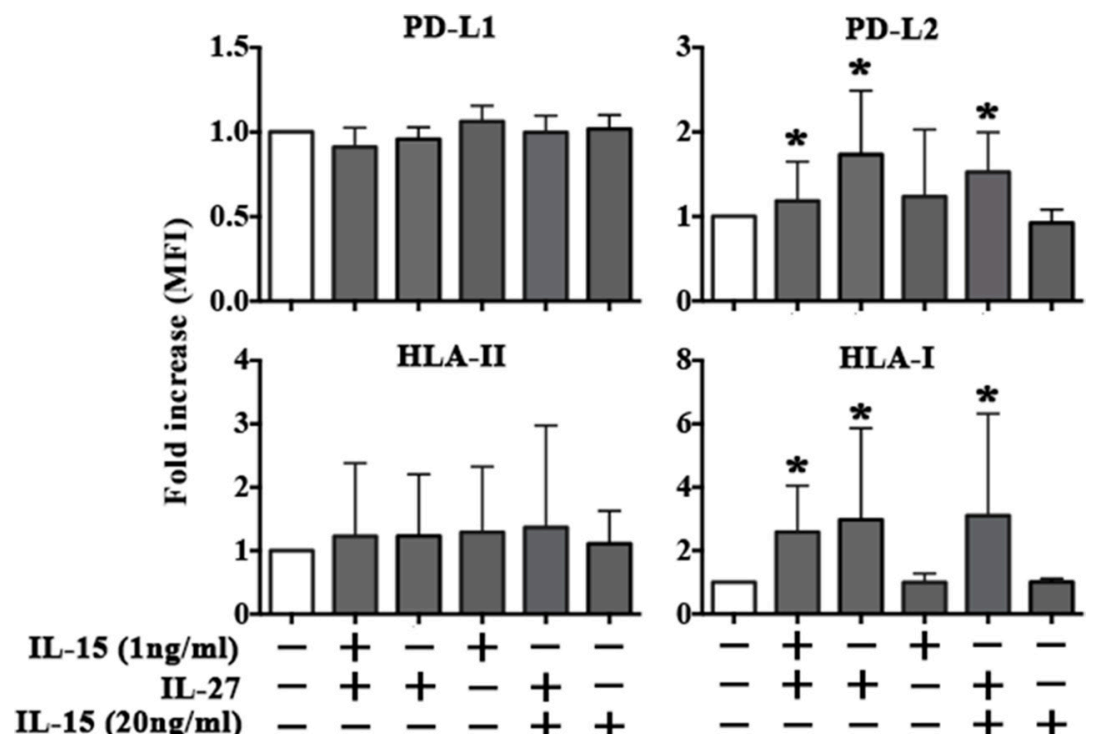

Figure 7: rIL-27 upregulates PD-L2 and HLA-I in EA cell line. The EA cell line untreated (white bar) or treated with rIL-15 and rIL-27 alone or in combination (gray bars) was analyzed by flow cytometry for the expression of PD-Ls, HLA-II and HLA-I. MFI fold increase is shown. Mean and $95 \%$ confidence intervals are indicated. ${ }^{*} p<0.05$. Data shown are pooled from 4 independent experiments. 
for at least one passage and their purity was confirmed by flow cytometry (FACScalibur, Becton Dickinson and Co, Mountain View, CA) analyzing the presence of the ECs markers factor VIII-related antigen (anti-human Von Willebrand factor mAb, Beckman Coulter, Marseille, France) and CD105 (anti-human CD105 mAb, Beckman Coulter), and the absence of CD14 (anti-human CD14 mAb, Becton Dickinson) and CD38 (anti-human CD38 $\mathrm{mAb}$, Becton Dickinson) molecules. ECs viability was assessed by trypan blue exclusion staining ( $>97 \%$ viable cells). The human endothelial (EA.hy926, henceforth named EA) and erythroleukemia (K562) cell lines were purchased from American Type Culture Collection (ATCC).

After approval by the Ethics Board (N³9/2012) and informed consent, buffy coats were obtained from healthy volunteer blood donors admitted at the transfusion center of IRCCS AOU San Martino-IST (Genova, Italy). Peripheral blood mononuclear cells (PBMC) were isolated on FicollHypaque gradients and frozen at $-80^{\circ} \mathrm{C}$. Upon arrival of
MMECs in the laboratory by express courier, PBMC were thawed and either stimulated with cytokines or used to purify NK cells (Human NK Cell Isolation kit, Miltenyi Biotec, GmbH, Bergisch Gladbach, Germany) as previously described [53]. The degree of purity of the isolated NK cells (CD3-, CD56 ${ }^{+}, \mathrm{NKp}^{-} 6^{+}$) was superior to $98 \%$.

\section{Monoclonal antibodies and cytokines}

The following $\mathrm{mAbs}$ were produced in our laboratory: A6136 (IgM) and 6A4 (IgG1) (anti-HLA class I-A, -B, -C and HLA-E), FST24 (IgG2b, anti-HLA-II), A6/220 (IgM, anti-CD56), BAB281 (IgG1) and KL247 (IgM) (antiNKp46), AZ20 (IgG1) and F252 (IgM) (anti-NKp30), BAT221 (IgG1, anti-NKG2D), KRA236 (IgG1) and F5 (IgM) (anti-DNAM-1), BAM195 (IgG1, anti-MICA), M5A10 (IgG1, anti-PVR), U191 (IgM, anti-Nectin-2), c227 (IgG1, anti-CD69). MAB1380 (IgG2a, anti-ULBP1), MAB163903 (IgG2A, anti-ULBP2), MAB1517 (IgG2A,
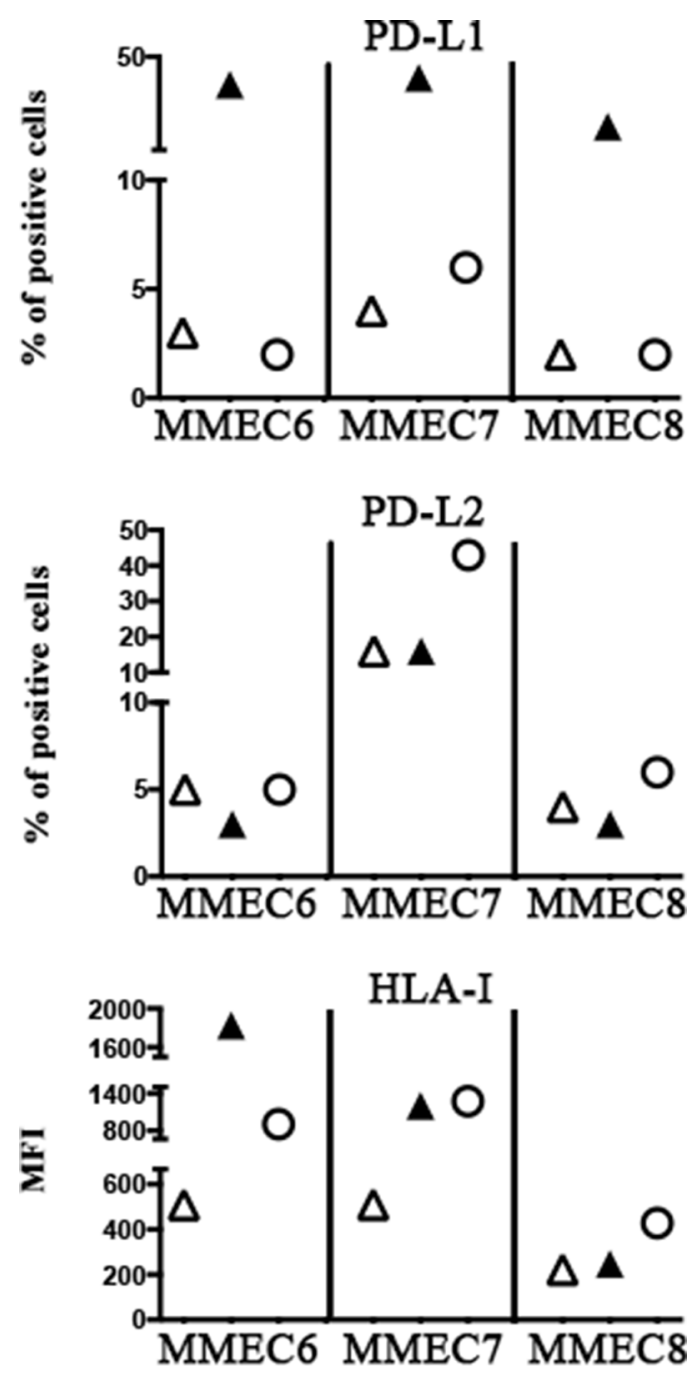

Figure 8: Effect of rIL-27 on PD-Ls and HLA-I expression in MMECs. Three MMECs either untreated (open triangle) or treated for 5 days with IFN- $\gamma$ (black triangle) or IL-27 (open circle) were analyzed by flow cytometry for the expression of PD-Ls and HLA-I. Percentage of positive cells or MFI is indicated. 
anti-ULBP3) and M475 (IgG2B, anti-ULBP4) mAbs were purchased from R\&D System Inc., (Minneapolis, MN, USA); anti-CD107a-PE and anti-CD56-PC5 mAbs were purchased from Becton Dickinson. Anti-PD-L1.3.1 (IgG1, anti-PD-L1) and anti-PD-L2 (IgG1, anti-PD-L2) were generated in D. Olive's lab.

Human recombinant cytokines were purchased from PeproTech (rIL-15, rIFN- $\gamma$ and rTNF $\alpha$ ) MBL International (rIL-18) and R\&D Systems (rIL-27).

\section{Flow cytometry, cytolytic and ELISA assays}

For one-color immunofluorescence and cytofluorimetric analysis (FACSCalibur Becton Dickinson) cells were stained with the appropriate mAbs or isotype matched controls followed by PE-isotype-specific goat antimouse second reagent (Southern Biotechnology Associated, Birmingham, AL). On every experimental session, the flow cytometer performances were monitored and the reproducibility of the fluorescence intensity was aligned by calibrated microsphere (Becton Dickinson). ECs were gated on the basis of physical parameters $(\mathrm{SSC}=$ Side Scatter; $\mathrm{FSC}=$ Forward scatter) to detect viable cells. To verify the appropriateness of the gating strategy cells were stained (10 minutes at the room temperature) with Annexin V and ToPro-3 Iodide (Life Technologies, CA, USA).

Purified NK cells were cultured for 2 days in the presence of recombinant cytokines to obtain polyclonal activated NK cell populations, which were analyzed for their cytolytic activity against target cells using a $4 \mathrm{~h}{ }^{51} \mathrm{Cr}$ release assay [21]. For CD107a (LAMP-1) degranulation assay NK cells were incubated for three hours with target cells in the presence of a PE-conjugated anti-human CD107a (IgG1; BD Biosciences).

The IFN- $\gamma$ enzyme-linked immunosorbent human assay (ELISA) was performed according to the manufacturer's instruction (Life Technologies).

\section{Cell transfectants and chimeric receptors}

The BW5147/B7-H6+ stable cell transfectant was prepared by retrovirus gene transfer using a B7-H6 ORF cDNA obtained by RT-PCR from the MM6 human myelomonocytic cell line and subcloned in pMXs-IG (IRES-GFP) retrovirus vector (kindly provided by Dr. Kitamura, Tokyo, Japan). The empty vector pMXs-IG was used to generate the negative control (mock cell transfectant). DNAM1-Fc and NKp30-Fc were obtained in our lab fusing the extracellular region of the receptor with a mutated human IgG1 Fc portion that lack the ability to bind FcRs $[52,73]$.

\section{Real-time PCR}

Total RNA was extracted from K562 and EA cell lines and from immature dendritic cells (iDC) using
RNAeasy Mini Kit (Qiagen, Hilden, Germany) according to manufacturer's instructions. Starting from $1 \mu \mathrm{g}$ RNA, oligodT-primed cDNA was prepared using Transcriptor First Strand Synthesis Kit (Roche diagnostic, Mannheim, Germany). The expression of B7-H6 and HPRT1 (hypoxanthine phosphoribosyltransferase 1) transcripts was assessed by real-time PCR with the Taqman Gene expression assays (Hs02340611_m1 and Hs99999909 m1, respectively) and Express qPCR SuperMix (Thermo Fisher Scientific, Waltham, MA, USA). Samples were run on a ViiA 7 Real-Time PCR System (Thermo Fisher Scientific). Each reaction was performed in triplicate and each sample was analysed in three independent experiments. Relative expression of B7-H6 transcript was determined in each sample by normalization with respect to the HPRT1 gene, according to the standard $\Delta \mathrm{C}_{\mathrm{T}}$ method.

\section{Statistical analysis}

Statistical analysis with level of significance (p) and graphic representation were performed using WilcoxonMann-Whiteny $p$-value test (non-parametric significance test) and GraphPad Prism 6 (GraphPad Software La Jolla, CA).

\section{ACKNOWLEDGMENTS AND FUNDING}

This work was supported by the Associazione Italiana per la Ricerca sul Cancro (AIRC): Investigator Grant (no. 14095) and Special Program Molecular Clinical Oncology 5 per 1000 (no. 9965) to AV; Investigator Grant (no. 15704) and Special Program Molecular Clinical Oncology 5 per 1000 (no.9962) to AM. DO laboratory is supported by Fondation pour la Recherche Médicale (Equipe FRM DEQ20140329534). DO is a senior scholar of the Institut Universitaire de France. F. Bellora is recipient of a fellowship awarded by AIRC.

\section{CONFLICTS OF INTEREST}

D.Olive is co-founder of Imcheck Therapeutics (Marseille, France). A. Moretta is founder and shareholder of Innate Pharma (Marseille, France). The remaining authors declare no conflicts of interest.

\section{REFERENCES}

1. Ribatti D, Nico B, Vacca A. Multiple myeloma as a model for the role of bone marrow niches in the control of angiogenesis. Int Rev Cell Mol Biol. 2015; 314:259-282.

2. Vivier E, Raulet DH, Moretta A, Caligiuri MA, Zitvogel L, Lanier LL, Yokoyama WM, Ugolini S. Innate or adaptive immunity? The example of natural killer cells. Science. 2011; 331:44-49. 
3. Bottino C, Dondero A, Bellora F, Moretta L, Locatelli F, Pistoia V, Moretta A, Castriconi R. Natural killer cells and neuroblastoma: tumor recognition, escape mechanisms, and possible novel immunotherapeutic approaches. Front Immunol. 2014; 5:56.

4. Terme M, Ullrich E, Delahaye NF, Chaput N, Zitvogel L. Natural killer cell-directed therapies: moving from unexpected results to successful strategies. Nat Immunol. 2008; 9:486-494.

5. Moretta L, Pietra G, Vacca P, Pende D, Moretta F, Bertaina A, Mingari MC, Locatelli F, Moretta A. Human Nk Cells: From Surface Receptors to Clinical Applications. Immunol Lett. 2016.

6. Spits H, Artis D, Colonna M, Diefenbach A, Di Santo JP, Eberl G, Koyasu S, Locksley RM, McKenzie AN, Mebius RE, Powrie F, Vivier E. Innate lymphoid cells - a proposal for uniform nomenclature. Nat Rev Immunol. 2013; 13:145-149.

7. Montaldo E, Vacca P, Vitale C, Moretta F, Locatelli F, Mingari MC, Moretta L. Human innate lymphoid cells. Immunol Lett. 2016.

8. Castriconi R, Daga A, Dondero A, Zona G, Poliani PL, Melotti A, Griffero F, Marubbi D, Spaziante R, Bellora F, Moretta L, Moretta A, Corte G, et al. NK cells recognize and kill human glioblastoma cells with stem cell-like properties. J Immunol. 2009; 182:3530-3539.

9. Castriconi R, Dondero A, Negri F, Bellora F, Nozza P, Carnemolla B, Raso A, Moretta L, Moretta A, Bottino C. Both CD133+ and CD133- medulloblastoma cell lines express ligands for triggering $\mathrm{NK}$ receptors and are susceptible to NK-mediated cytotoxicity. Eur J Immunol. 2007; 37:3190-3196.

10. Pietra G, Manzini C, Vitale M, Balsamo M, Ognio E, Boitano M, Queirolo P, Moretta L, Mingari MC. Natural killer cells kill human melanoma cells with characteristics of cancer stem cells. Int Immunol. 2009; 21:793-801.

11. Ames E, Canter RJ, Grossenbacher SK, Mac S, Smith RC, Monjazeb AM, Chen M, Murphy WJ. Enhanced targeting of stem-like solid tumor cells with radiation and natural killer cells. Oncoimmunology. 2015; 4:e1036212.

12. Raulet DH, Gasser S, Gowen BG, Deng W, Jung H. Regulation of ligands for the NKG2D activating receptor. Annu Rev Immunol. 2013; 31:413-441.

13. Pietra G, Vitale C, Pende D, Bertaina A, Moretta F, Falco M, Vacca P, Montaldo E, Cantoni C, Mingari MC, Moretta A, Locatelli F, Moretta L. Human natural killer cells: news in the therapy of solid tumors and high-risk leukemias. Cancer Immunol Immunother. 2016; 65:465-476.

14. Koch J, Steinle A, Watzl C, Mandelboim O. Activating natural cytotoxicity receptors of natural killer cells in cancer and infection. Trends Immunol. 2013; 34:182-191.

15. Baychelier F, Sennepin A, Ermonval M, Dorgham K, Debre P, Vieillard V. Identification of a cellular ligand for the natural cytotoxicity receptor NKp44. Blood. 2013; 122:2935-2942.
16. Brandt CS, Baratin M, Yi EC, Kennedy J, Gao Z, Fox B, Haldeman B, Ostrander CD, Kaifu T, Chabannon C, Moretta A, West R, Xu W, et al. The B7 family member B7-H6 is a tumor cell ligand for the activating natural killer cell receptor NKp30 in humans. J Exp Med. 2009; 206:1495-1503.

17. Fiegler N, Textor S, Arnold A, Rolle A, Oehme I, Breuhahn K, Moldenhauer G, Witzens-Harig $M$, Cerwenka A. Downregulation of the activating NKp30 ligand B7-H6 by HDAC inhibitors impairs tumor cell recognition by NK cells. Blood. 2013; 122:684-693.

18. Bottino C, Castriconi R, Pende D, Rivera P, Nanni M, Carnemolla B, Cantoni C, Grassi J, Marcenaro S, Reymond N, Vitale M, Moretta L, Lopez M, et al. Identification of PVR (CD155) and Nectin-2 (CD112) as cell surface ligands for the human DNAM-1 (CD226) activating molecule. J Exp Med. 2003; 198:557-567.

19. Fuchs A, Cella M, Giurisato E, Shaw AS, Colonna M. Cutting edge: CD96 (tactile) promotes NK cell-target cell adhesion by interacting with the poliovirus receptor (CD155). J Immunol. 2004; 172:3994-3998.

20. Stanietsky N, Simic H, Arapovic J, Toporik A, Levy O, Novik A, Levine Z, Beiman M, Dassa L, Achdout H, Stern-Ginossar N, Tsukerman P, Jonjic S, et al. The interaction of TIGIT with PVR and PVRL2 inhibits human NK cell cytotoxicity. Proc Natl Acad Sci USA. 2009; 106:17858-17863.

21. Castriconi R, Dondero A, Corrias MV, Lanino E, Pende D, Moretta L, Bottino C, Moretta A. Natural killer cellmediated killing of freshly isolated neuroblastoma cells: critical role of DNAX accessory molecule-1-poliovirus receptor interaction. Cancer Res. 2004; 64:9180-9184.

22. Carlsten M, Bjorkstrom NK, Norell H, Bryceson Y, van Hall T, Baumann BC, Hanson M, Schedvins K, Kiessling R, Ljunggren HG, Malmberg KJ. DNAX accessory molecule-1 mediated recognition of freshly isolated ovarian carcinoma by resting natural killer cells. Cancer Res. 2007; 67:1317-1325.

23. Iguchi-Manaka A, Kai H, Yamashita Y, Shibata K, TaharaHanaoka S, Honda S, Yasui T, Kikutani H, Shibuya K, Shibuya A. Accelerated tumor growth in mice deficient in DNAM-1 receptor. J Exp Med. 2008; 205:2959-2964.

24. Chan CJ, Andrews DM, McLaughlin NM, Yagita H, Gilfillan S, Colonna M, Smyth MJ. DNAM-1/CD155 interactions promote cytokine and NK cell-mediated suppression of poorly immunogenic melanoma metastases. J Immunol. 2010; 184:902-911.

25. Hou S, Ge K, Zheng X, Wei H, Sun R, Tian Z. CD226 protein is involved in immune synapse formation and triggers Natural Killer (NK) cell activation via its first extracellular domain. J Biol Chem. 2014; 289:6969-6977.

26. Castriconi R, Dondero A, Cantoni C, Della Chiesa M, Prato C, Nanni M, Fiorini M, Notarangelo L, Parolini S, Moretta L, Notarangelo L, Moretta A, Bottino C. Functional 
characterization of natural killer cells in type I leukocyte adhesion deficiency. Blood. 2007; 109:4873-4881.

27. Ramsbottom KM, Hawkins ED, Shimoni R, McGrath M, Chan CJ, Russell SM, Smyth MJ, Oliaro J. Cutting edge: DNAX accessory molecule 1-deficient CD8+ T cells display immunological synapse defects that impair antitumor immunity. J Immunol. 2014; 192:553-557.

28. Enqvist M, Ask EH, Forslund E, Carlsten M, Abrahamsen G, Beziat V, Andersson S, Schaffer M, Spurkland A, Bryceson Y, Onfelt B, Malmberg KJ. Coordinated expression of DNAM-1 and LFA-1 in educated NK cells. J Immunol. 2015; 194:4518-4527.

29. Yoshida H, Hunter CA. The immunobiology of interleukin-27. Annu Rev Immunol. 2015; 33:417-443.

30. Murugaiyan G, Saha B. IL-27 in tumor immunity and immunotherapy. Trends Mol Med. 2013; 19:108-116.

31. Shimizu M, Shimamura M, Owaki T, Asakawa M, Fujita K, Kudo M, Iwakura Y, Takeda Y, Luster AD, Mizuguchi J, Yoshimoto T. Antiangiogenic and antitumor activities of IL-27. J Immunol. 2006; 176:7317-7324.

32. Balsamo M, Vermi W, Parodi M, Pietra G, Manzini C, Queirolo P, Lonardi S, Augugliaro R, Moretta A, Facchetti F, Moretta L, Mingari MC, Vitale M. Melanoma cells become resistant to NK-cell-mediated killing when exposed to NKcell numbers compatible with NK-cell infiltration in the tumor. Eur J Immunol. 2012; 42:1833-1842.

33. Bellucci R, Martin A, Bommarito D, Wang K, Hansen SH, Freeman GJ, Ritz J. Interferon-gamma-induced activation of JAK1 and JAK2 suppresses tumor cell susceptibility to NK cells through upregulation of PD-L1 expression. Oncoimmunology. 2015; 4:e1008824.

34. Pardoll DM. The blockade of immune checkpoints in cancer immunotherapy. Nat Rev Cancer. 2012; 12:252-264.

35. Shin DS, Ribas A. The evolution of checkpoint blockade as a cancer therapy: what's here, what's next? Curr Opin Immunol. 2015; 33:23-35.

36. Buque A, Bloy N, Aranda F, Castoldi F, Eggermont A, Cremer I, Fridman WH, Fucikova J, Galon J, Marabelle A, Spisek R, Tartour E, Zitvogel L, et al. Trial Watch: Immunomodulatory monoclonal antibodies for oncological indications. Oncoimmunology. 2015; 4:e1008814.

37. Vacca A, Ria R, Semeraro F, Merchionne F, Coluccia M, Boccarelli A, Scavelli C, Nico B, Gernone A, Battelli F, Tabilio A, Guidolin D, Petrucci MT, et al. Endothelial cells in the bone marrow of patients with multiple myeloma. Blood. 2003; 102:3340-3348.

38. Matta J, Baratin M, Chiche L, Forel JM, Cognet C, Thomas G, Farnarier C, Piperoglou C, Papazian L, Chaussabel D, Ugolini S, Vely F, Vivier E. Induction of B7-H6, a ligand for the natural killer cell-activating receptor NKp30, in inflammatory conditions. Blood. 2013; 122:394-404.

39. Vitale M, Della Chiesa M, Carlomagno S, Pende D, Arico M, Moretta L, Moretta A. NK-dependent DC maturation is mediated by TNFalpha and IFNgamma released upon engagement of the NKp30 triggering receptor. Blood. 2005; 106:566-571.

40. Taube JM, Anders RA, Young GD, Xu H, Sharma R, McMiller TL, Chen S, Klein AP, Pardoll DM, Topalian SL, Chen L. Colocalization of inflammatory response with B7-h1 expression in human melanocytic lesions supports an adaptive resistance mechanism of immune escape. Sci Transl Med. 2012; 4:127ra137.

41. Brenner H, Gondos A, Pulte D. Recent major improvement in long-term survival of younger patients with multiple myeloma. Blood. 2008; 111:2521-2526.

42. Krieg S, Ullrich E. Novel immune modulators used in hematology: impact on NK cells. Front Immunol. 2012; 3:388.

43. Benson DM Jr, Bakan CE, Mishra A, Hofmeister CC, Efebera Y, Becknell B, Baiocchi RA, Zhang J, Yu J, Smith MK, Greenfield CN, Porcu P, et al. The PD-1/PD-L1 axis modulates the natural killer cell versus multiple myeloma effect: a therapeutic target for CT-011, a novel monoclonal anti-PD-1 antibody. Blood. 2010; 116:2286-2294.

44. Benson DM Jr, Cohen AD, Jagannath S, Munshi NC, Spitzer G, Hofmeister CC, Efebera YA, Andre P, Zerbib R, Caligiuri MA. A Phase I Trial of the Anti-KIR Antibody IPH2101 and Lenalidomide in Patients with Relapsed/ Refractory Multiple Myeloma. Clin Cancer Res. 2015; 21:4055-4061.

45. Carbone E, Neri P, Mesuraca M, Fulciniti MT, Otsuki T, Pende D, Groh V, Spies T, Pollio G, Cosman D, Catalano L, Tassone P, Rotoli B, et al. HLA class I, NKG2D, and natural cytotoxicity receptors regulate multiple myeloma cell recognition by natural killer cells. Blood. 2005; 105:251-258.

46. El-Sherbiny YM, Meade JL, Holmes TD, McGonagle D, Mackie SL, Morgan AW, Cook G, Feyler S, Richards SJ, Davies FE, Morgan GJ, Cook GP. The requirement for DNAM-1, NKG2D, and NKp46 in the natural killer cellmediated killing of myeloma cells. Cancer Res. 2007; 67:8444-8449.

47. Soriani A, Fionda C, Ricci B, Iannitto ML, Cippitelli M, Santoni A. Chemotherapy-elicited upregulation of NKG2D and DNAM-1 ligands as a therapeutic target in multiple myeloma. Oncoimmunology. 2013; 2:e26663.

48. Soriani A, Zingoni A, Cerboni C, Iannitto ML, Ricciardi MR, Di Gialleonardo V, Cippitelli M, Fionda C, Petrucci MT, Guarini A, Foa R, Santoni A. ATM-ATRdependent up-regulation of DNAM-1 and NKG2D ligands on multiple myeloma cells by therapeutic agents results in enhanced NK-cell susceptibility and is associated with a senescent phenotype. Blood. 2009; 113:3503-3511.

49. Ribatti D, Moschetta M, Vacca A. Microenvironment and multiple myeloma spread. Thromb Res. 2014; 133:S102-106.

50. Pilarski LM, Pilarski PM, Belch AR. Multiple myeloma may include microvessel endothelial cells of malignant origin. Leuk Lymphoma. 2010; 51:592-597.

51. Martinet L, Smyth MJ. Balancing natural killer cell activation through paired receptors. Nat Rev Immunol. $2015 ; 15: 243-254$. 
52. Reymond N, Imbert AM, Devilard E, Fabre S, Chabannon C, Xerri L, Farnarier C, Cantoni C, Bottino C, Moretta A, Dubreuil P, Lopez M. DNAM-1 and PVR regulate monocyte migration through endothelial junctions. J Exp Med. 2004; 199:1331-1341.

53. Bellora F, Castriconi R, Dondero A, Pessino A, Nencioni A, Liggieri G, Moretta L, Mantovani A, Moretta A, Bottino C. TLR activation of tumor-associated macrophages from ovarian cancer patients triggers cytolytic activity of NK cells. Eur J Immunol. 2014; 44:1814-1822.

54. Allavena P, Sica A, Garlanda C, Mantovani A. The YinYang of tumor-associated macrophages in neoplastic progression and immune surveillance. Immunol Rev. 2008; 222:155-161.

55. Sloan KE, Eustace BK, Stewart JK, Zehetmeier C, Torella C, Simeone M, Roy JE, Unger C, Louis DN, Ilag LL, Jay DG. CD155/PVR plays a key role in cell motility during tumor cell invasion and migration. BMC Cancer. 2004; 4:73.

56. Enloe BM, Jay DG. Inhibition of Necl-5 (CD155/PVR) reduces glioblastoma dispersal and decreases MMP-2 expression and activity. J Neurooncol. 2011; 102:225-235.

57. Atsumi S, Matsumine A, Toyoda H, Niimi R, Iino T, Sudo A. Prognostic significance of CD155 mRNA expression in soft tissue sarcomas. Oncol Lett. 2013; 5:1771-1776.

58. Pende D, Castriconi R, Romagnani P, Spaggiari GM, Marcenaro S, Dondero A, Lazzeri E, Lasagni L, Martini S, Rivera P, Capobianco A, Moretta L, Moretta A, et al. Expression of the DNAM-1 ligands, Nectin-2 (CD112) and poliovirus receptor (CD155), on dendritic cells: relevance for natural killer-dendritic cell interaction. Blood. 2006; 107:2030-2036.

59. Chijioke O, Munz C. Dendritic cell derived cytokines in human natural killer cell differentiation and activation. Front Immunol. 2013; 4:365.

60. Bellora F, Castriconi R, Dondero A, Reggiardo G, Moretta L, Mantovani A, Moretta A, Bottino C. The interaction of human natural killer cells with either unpolarized or polarized macrophages results in different functional outcomes. Proc Natl Acad Sci USA. 2010; 107:21659-21664.

61. Romo N, Magri G, Muntasell A, Heredia G, Baia D, Angulo A, Guma M, Lopez-Botet M. Natural killer cellmediated response to human cytomegalovirus-infected macrophages is modulated by their functional polarization. J Leukoc Biol. 2011; 90:717-726.

62. Fehniger TA, Cooper MA, Caligiuri MA. Interleukin-2 and interleukin-15: immunotherapy for cancer. Cytokine Growth Factor Rev. 2002; 13:169-183.

63. Pulliam SR, Uzhachenko RV, Adunyah SE, Shanker A. Common gamma chain cytokines in combinatorial immune strategies against cancer. Immunol Lett. 2016; 169:61-72.

64. Kuniyasu H, Ohmori H, Sasaki T, Sasahira T, Yoshida K, Kitadai Y, Fidler IJ. Production of interleukin 15 by human colon cancer cells is associated with induction of mucosal hyperplasia, angiogenesis, and metastasis. Clin Cancer Res. 2003; 9:4802-4810.

65. Villadsen LS, Schuurman J, Beurskens F, Dam TN, Dagnaes-Hansen F, Skov L, Rygaard J, VoorhorstOgink MM, Gerritsen AF, van Dijk MA, Parren PW, Baadsgaard $\mathrm{O}$ and van de Winkel JG. Resolution of psoriasis upon blockade of IL-15 biological activity in a xenograft mouse model. J Clin Invest. 2003; 112:1571-1580.

66. Ziblat A, Domaica CI, Spallanzani RG, Iraolagoitia XL, Rossi LE, Avila DE, Torres NI, Fuertes MB, Zwirner NW. IL-27 stimulates human NK-cell effector functions and primes NK cells for IL-18 responsiveness. Eur J Immunol. 2015; 45:192-202.

67. Hibbert L, Pflanz S, De Waal Malefyt R, Kastelein RA. IL-27 and IFN-alpha signal via Stat1 and Stat3 and induce T-Bet and IL-12Rbeta 2 in naive $\mathrm{T}$ cells. $\mathrm{J}$ Interferon Cytokine Res. 2003; 23:513-522.

68. Zwirner NW, Ziblat A. Regulation of NK Cell Activation and Effector Functions by the IL-12 Family of Cytokines: The Case of IL-27. Front Immunol. 2017; 8:25.

69. Feng XM, Chen XL, Liu N, Chen Z, Zhou YL, Han ZB, Zhang L, Han ZC. Interleukin-27 upregulates major histocompatibility complex class II expression in primary human endothelial cells through induction of major histocompatibility complex class II transactivator. Hum Immunol. 2007; 68:965-972.

70. Carbotti G, Barisione G, Airoldi I, Mezzanzanica D, Bagnoli M, Ferrero S, Petretto A, Fabbi M, Ferrini S. IL-27 induces the expression of IDO and PD-L1 in human cancer cells. Oncotarget. 2015; 6:43267-43280. doi: 10.18632/ oncotarget.6530.

71. Dondero A, Pastorino F, Della Chiesa M, Corrias MV, Morandi F, Pistoia V, Olive D, Bellora F, Locatelli F, Castellano A, Moretta L, Moretta A, Bottino C, et al. PD-L1 expression in metastatic neuroblastoma as an additional mechanism for limiting immune surveillance. Oncoimmunology. 2016; 5:e1064578.

72. Pesce S, Greppi M, Tabellini G, Rampinelli F, Parolini S, Olive D, Moretta L, Moretta A, Marcenaro E. Identification of a subset of human natural killer cells expressing high levels of programmed death 1: A phenotypic and functional characterization. J Allergy Clin Immunol. 2017; 139:335-346 e333.

73. Vacca P, Cantoni C, Prato C, Fulcheri E, Moretta A, Moretta L, Mingari MC. Regulatory role of NKp44, NKp46, DNAM-1 and NKG2D receptors in the interaction between NK cells and trophoblast cells. Evidence for divergent functional profiles of decidual versus peripheral NK cells. Int Immunol. 2008; 20:1395-1405. 